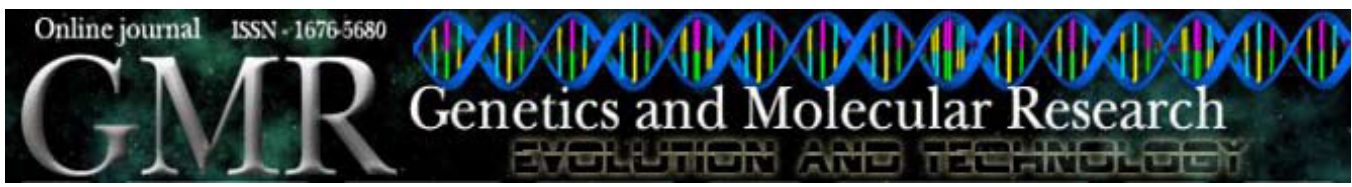

\title{
Origin of a polyploid accession of Brachiaria humidicola (Poaceae: Panicoideae: Paniceae)
}

\author{
K.R. Boldrini' ${ }^{1}$ P.L. Micheletti ${ }^{1}$, P.H. Gallo ${ }^{1}$, A.B. Mendes-Bonato ${ }^{1}$, \\ M.S. Pagliarini ${ }^{1}$ and C.B. Valle ${ }^{2}$ \\ ${ }^{1}$ Departamento de Biologia Celular e Genética, \\ Universidade Estadual de Maringá, Maringá, PR, Brasil \\ ${ }^{2}$ Embrapa Gado de Corte, Campo Grande, MS, Brasil \\ Corresponding author: M.S. Pagliarini \\ E-mail: mspagliarini@uem.br
}

Genet. Mol. Res. 8 (3): 888-895 (2009)

Received March 28, 2009

Accepted June 3, 2009

Published July 28, 2009

\begin{abstract}
Brachiaria humidicola, a species adapted to poorly drained and infertile acid soils, is widely used throughout the tropics. Cytological characterization of 54 accessions of $B$. humidicola for breeding purposes revealed $2 \mathrm{n}=36,42$, and 54 chromosomes. One accession (H030), with $2 \mathrm{n}$ $=42$ chromosomes, showed a different meiotic behavior. In most accessions from the genus Brachiaria previously studied, the basic chromosome number is $\mathrm{x}=9$, but the putative basic number in $\mathrm{H} 030$ appears to be $\mathrm{x}=6$. Since six univalent chromosomes were found in diakinesis and metaphase I, and these behaved as laggards in anaphase I, it was hypothesized that both genitors were derived from $\mathrm{x}=6$, and that this accession is a heptaploid $2 \mathrm{n}=7 \mathrm{x}=42$. The parental genomes did not have the same meiotic behavior, particularly during anaphase, when one genome consisting of six univalents remained as laggards and underwent sister-chromatid segregation. At telophase, 18 segregated chromosomes were found at each pole. The laggard genome did not reach the poles at telophase I or II in time to be included in the nucleus and was eliminated as micronuclei.
\end{abstract}

Key words: Allopolyploidy; Brachiaria humidicola; Chromosome elimination; Genome affinity; Meiotic behavior 


\section{INTRODUCTION}

Most flowering plant species have evolved through one or more rounds of polyploidy, either by doubling the chromosome number within a species (autopolyploidy) or by combining chromosome sets from distinct but related species (allopolyploidy) (Osborn, 2004). Although the most well-known examples of allopolyploidy in the literature are centered on events that occurred many millions of years ago (paleopolyploidy), polyploidy is an active and ongoing process in many plant genera (Adams and Wendel, 2005). However, it is still unclear precisely how polyploidy evolves, i.e., by what processes polyploids arise, are established, and persist in natural populations. The evolutionary success of polyploidy most directly requires the ability of polyploid individuals to reproduce and transfer their genes to subsequent generations (Pannell et al., 2004).

Gramineae is the only large family in which a high frequency of polyploids prevails. More than $80 \%$ of its members have undergone polyploidy at some time during their evolutionary history (Stebbins, 1985). However, both the ancestral chromosome numbers and trends in chromosomal evolution in grasses have been the subject of considerable speculation. The high frequency of polyploidy, particularly allopolyploidy and aneuploidy, a tendency for rediploidization and frequent hybridization between closely and distantly related species compound the difficulties in understanding the trends in Poaceae grasses. The wide range in basic chromosome number ( $\mathrm{x}=2$ to 18$)$ has resulted in contrasting views on chromosomal evolution in this family (Hilu, 2004).

In Brachiaria, a genus of forage grass of African origin comprising about 100 species, polyploidy was reported to be very frequent (Valle and Savidan, 1996; Penteado et al., 2000; Bernini and Marin-Morales, 2001; Utsunomiya et al., 2005; Mendes-Bonato et al., 2002, 2006). Tetraploidy $(2 n=4 x=36)$, derived from $x=9$, predominates among species and accessions in this genus, but a clear polyploid series exists, with diploid, tetra-, penta-, hexa-, and heptaploid accessions, reported for some species (Valle and Glienke, 1991; Penteado et al., 2000; Risso-Pascotto et al., 2003; Mendes-Bonato et al., 2002, 2006). Despite the high level of polyploidy prevailing in the genus, its origin has never been adequately investigated. Cytological evidence obtained from different species, such as chromosome pairing at diakinesis, indicates that autopolyploidy and allopolyploidy might have contributed to the evolution of some species (Mendes-Bonato et al., 2002, 2006; Utsunomiya et al., 2005; Risso-Pascotto et al., 2006a). Three pentaploid accessions of Bachiaria brizantha, in turn, have provided unequivocal evidence that they originated from allopolyploidy (Mendes et al., 2006; Risso-Pascotto et al., 2006b).

Cytological analysis underway in B. humidicola, a species adapted to poorly drained and infertile acid soils (Keller-Grein et al., 1996) and widely used throughout the tropics, has revealed a predominance of accessions with $2 \mathrm{n}=36,42$, and 54 chromosomes. In this paper, an accession with $2 \mathrm{n}=42$ with striking cytological characteristics is described.

\section{MATERIAL AND METHODS}

Fifty-four accessions of $B$. humidicola from the Embrapa Beef Cattle germplasm collection, which comprises about 60 accessions of this species collected in the wild African savannas by the International Center for Tropical Agriculture (CIAT) in Colombia in the 1980s, were previously analyzed. Site characteristics where accessions were cultivated in the field at Embrapa Beef Cattle Research Center at Campo Grande, State of Mato Grosso do Sul (Brazil) were: climate type Aw: tropical humid savanna; average annual precipitation of $1526 \mathrm{~mm}$; 
average temperature of $22^{\circ} \mathrm{C}$; altitude of $520 \mathrm{~m}$; latitude of $20^{\circ} 28^{\prime} \mathrm{S}$; longitude of $55^{\circ} 40^{\prime} \mathrm{W}$; poor dark red latossol (59\% sand; $8 \%$ silt; $33 \%$ clay; $\mathrm{pH} 4.2$ ).

Inflorescences for meiotic study were collected in a plot containing 16 plants representing the accession and fixed in a mixture of $95 \%$ ethanol, chloroform and propionic acid $(6: 3: 2)$ for $24 \mathrm{~h}$, transferred to $70 \%$ alcohol and stored under refrigeration until use. Microsporocytes were prepared by squashing and staining with $0.5 \%$ propionic carmine. Photomicrographs were made with a Wild Leitz microscope using Kodak Imagelink - HQ, ISO 25 black and white film.

\section{RESULTS}

A total of 2365 cells were recorded from the evaluation of microsporogenesis in $\mathrm{H} 030$ (BRA005070) accession. The number of meiocytes evaluated in each meiotic phase and the number of abnormal cells are presented in Table 1. The percentage of abnormal cells was high in all meiotic phases. The main meiotic abnormalities were related to irregular chromosome orientation at the plate in metaphases and laggards at anaphases, leading to the formation of micronuclei in telophases.

\begin{tabular}{|c|c|c|}
\hline Phase & No. of cells analyzed & Abnormalities - Number of abnormal cells (\%) \\
\hline Diakinesis & 51 & Six univalents - 51 (100.0) \\
\hline Metaphase I & 339 & Delayed univalents - 245 (72.8) \\
\hline Anaphase I & 320 & Laggard genome - 314 (98.1) \\
\hline Telophase I & 291 & Two or more micronuclei - 272 (93.5) \\
\hline Prophase II & 259 & Micronuclei - 249 (96.1) \\
\hline Metaphase II & 315 & Micronuclei - 217 (68.9) \\
\hline Anaphase II & 210 & Laggard genome - 183 (87.1) \\
\hline Telophase II & 273 & Micronuclei - 203 (89.8) \\
\hline Tetrad & 358 & Micronuclei - 305 (85.2) \\
\hline
\end{tabular}

Pachytene cells showed one or two nucleoli (Figure 1a); when single, the nucleolus was bigger than when there were two. Chromosome counts at several anaphase I in well-spread preparations revealed $2 \mathrm{n}=42$ chromosomes (Figure $1 \mathrm{~b}$ ). In spite of less than ideal diakinesis configurations for accurate analysis of chromosome pairing, six univalents, predominance of bivalents, and some multivalents were recorded among the cells (Figure 1c). The six univalents could also be easily detected among paired chromosomes at the equatorial plate in metaphase I and were always delayed in reaching their position in the metaphase plate (Figure 1d,e). The majority of cells in this phase displayed normal behavior. In anaphase I, while the major genome segregated to the poles, the six univalents remained as laggards at the metaphase plate (Figure 1f). In this phase, it was possible to count 18 segregated chromosomes at each pole and six univalents at the plate (Figure 1g). Subsequently, univalent chromosomes underwent sister-chromatid segregation and the segregated homologous chromosomes reached the poles (Figure 1g,h). In early telophase, the laggard genome showed a typical anaphase behavior with chromosomes closely aligned with the main nucleus (Figure 1i). In the majority of cells, the laggard genome did not reach the poles in time to be included in the main nucleus (Figure 1j). In some cells, however, univalents did not occupy the metaphase plate 


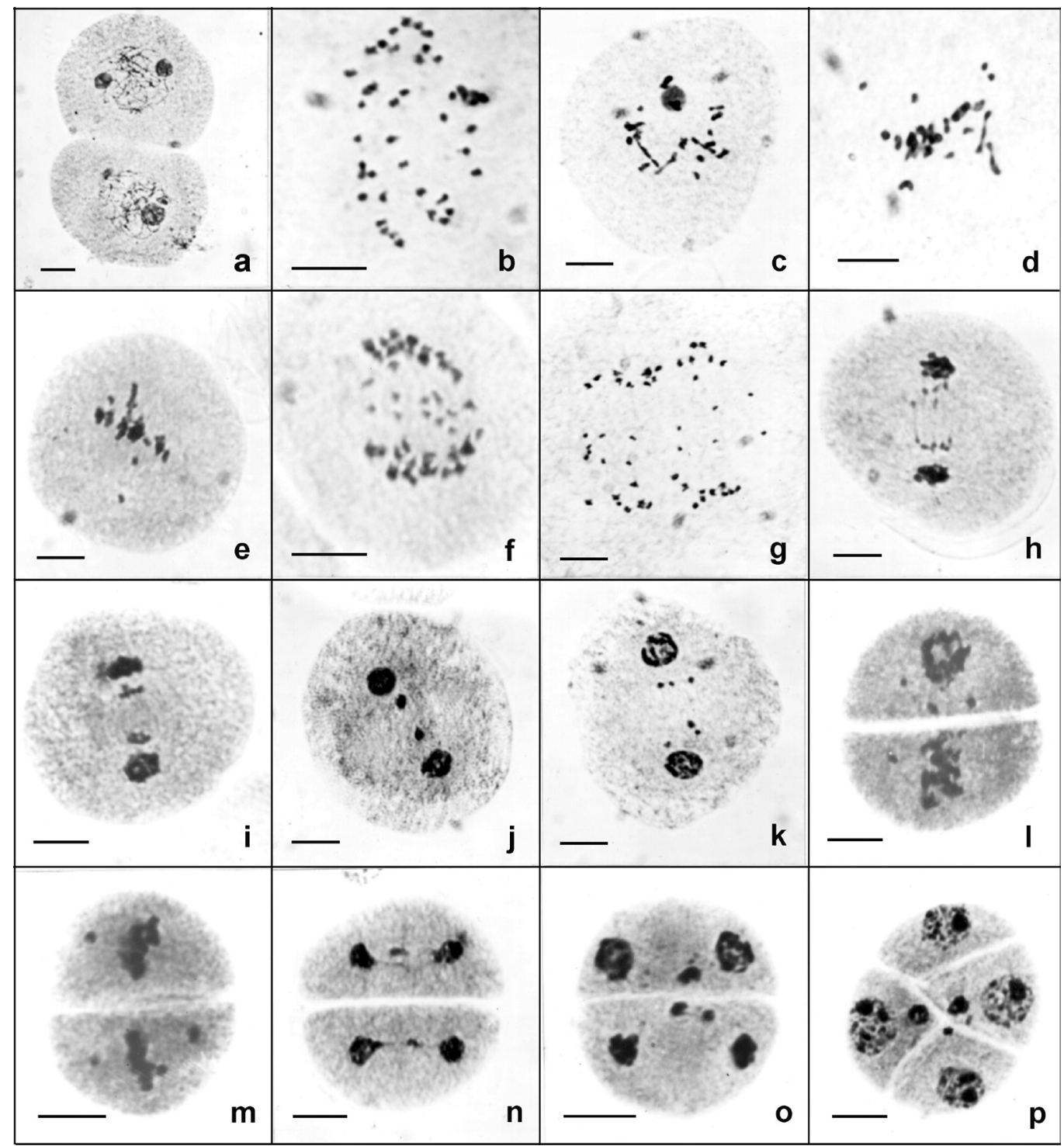

Figure 1. Aspects of meiotic behavior in H030. a. Microsporocytes in pachytene with one and two nucleoli. b. Early metaphase I showing 42 chromosomes. c. Diakinesis showing six univalents, bivalents and multivalents. d. Metaphase I with six non-oriented univalents. e. Metaphase I showing some delayed univalents. f, g. Anaphase I showing the six laggard univalents. Note that univalents underwent sister-chromatid segregation. It is possible to count 18 segregated chromosomes at each pole. h. Early telophase I with the laggard genome in anaphase I. i, j. Telophase I with the laggard genome in anaphase (i) and micronuclei (j). k. Telophase I showing six micronuclei from univalents that did not undergo sister-chromatid segregation. l. Prophase II with several micronuclei. $\mathbf{m}$. Metaphase II with micronuclei. n. Late anaphase II with laggard chromosomes. o. Telophase II with micronuclei. p. Tetrad with micronuclei of different sizes in three microspores. Scale bar $=19 \mu \mathrm{m}$. 
in time to undergo sister-chromatid segregation; they remained as univalents and formed one to six micronuclei between the main telophase nuclei (Figure 1k). In the second division, the behavior of genomes was the same. In prophase II, the persisting micronuclei were also visualized (Figure 11). In metaphase II, however, the laggard genome was not incorporated into the metaphase plate of the other genome and micronuclei could be observed (Figure $1 \mathrm{~m}$ ). In anaphase II, while the 18 segregated chromosomes underwent normal sister-chromatid segregation, the other genome remained as a laggard (Figure 1n). The migration of these chromatids remained asynchronous in relation to the other genome and also among themselves giving rise to micronuclei of different sizes in telophase II (Figure 1o) and tetrad (Figure 1p).

\section{DISCUSSION}

Cytological studies underway in the accessions of the $B$. humidicola collection revealed the presence of accessions with $2 \mathrm{n}=36,42$, and 54 chromosomes. Two basic chromosome numbers, $\mathrm{x}=7$ and $\mathrm{x}=9$, have been generally accepted for the genus Brachiaria with a large predominance of $\mathrm{x}=9$ (Basappa et al., 1987; Valle and Savidan, 1996; Bernini and Marin-Morales, 2001; Utsunomiya et al., 2005; Mendes-Bonato et al., 2002, 2006). However, a new basic chromosome number, $\mathrm{x}=6$, was recently reported in B. dictyoneura (RissoPascotto et al., 2006a).

The wide variation in basic chromosome number in grasses $(\mathrm{x}=2$ to 18$)$ has resulted in extensive controversy on the polarity and trends of chromosome evolution. According to Hilu (2004), the lack of robust phylogeny and empirical approaches have resulted in ambiguous assertions in chromosomal evolution in Poaceae. Sharma (1979) argued in favor of $x=6$ as the most ancestral chromosome number. Stebbins (1985), however, proposed $x=5,6$, and 7 as the complements of the now extinct species complex that gave rise to the Poaceae. Currently, most common are secondary diploids $(\mathrm{x}=10,12$, and 14$)$ derived through polyploidy (secondary polyploidy hypothesis), and $\mathrm{x}=9$, as found in Brachiaria, is probably derived via aneuploidy from $\mathrm{x}=10$, which in turn represents a diploidized tetraploid number from $\mathrm{x}=5$. Especially in the Poaceae, distinct chromosomal series found among subfamilies underscore the remarkable flexibility in genomic evolution. In the Panicoideae subfamily, where the Brachiaria genus is included, $\mathrm{x}=5,6,7,9,10,12$, and 14 can be found. However, the predominant basic numbers in the core Panicoideae are $x=9$ and 10 , with $x=10$ in $21 \%$ of the species and $x=9$ in most of the remaining taxa (De Wet, 1987).

Asynchronous meiosis, such as found in this accession of $B$. humidicola, has been reported in the genus Brachiaria. It occurred in an interspecific triploid hybrid between $B$. brizantha $(2 \mathrm{n}=4 \mathrm{x}=36$, apomictic male) and B. ruziziensis $(2 \mathrm{n}=2 \mathrm{x}=18$, sexual female), with genome elimination of the latter as laggard chromosomes (Risso-Pascotto et al., 2004). A similar meiotic behavior was described by Mendes et al. (2006) in two pentaploid accessions $(2 \mathrm{n}=5 \mathrm{x}=45)$ of $B$. brizantha. In these, pentaploidy was probably originated by natural hybridization between an apomictic tetraploid genitor producing unreduced male gametes and a sexual diploid female. The chromosomes of the female $(n=9)$ always remained as univalents in prophase I, underwent sister-chromatid segregation in anaphase I, and behaved as laggards. The haploid genome was always included in the nucleus, changing the nucleus shape. In the second division, however, the haploid genome did not get to the poles in time to be included in the nucleus, giving rise to several micronuclei. 
In B. humidicola $\mathrm{H} 030$, meiotic behavior was similar to those reported above. The six univalents typically behaved as laggards in anaphase I; however, they were not included in the main telophase nuclei, remaining as micronuclei. There is, however, a basic and fundamental difference between the present accession of $B$. humidicola and those of $B$. brizantha analyzed by Mendes et al. (2006). In the latter, all genomes were derived from $x=9$, and in $\mathrm{H} 030$ the chromosome constitution of $2 \mathrm{n}=42$ suggests different possible origins. Initially, the hypothesis was that the accession was a hexaploid $(2 \mathrm{n}=6 \mathrm{x}=42)$ derived from $\mathrm{x}=7$, the second most reported basic chromosome number in the genus Brachiaria, but never reported in B. humidicola. However, the constant occurrence of six univalents in diakinesis and in metaphase I in this accession, remaining as laggards in anaphase I, corroborated by the presence of 18 segregated chromosomes at each pole, led us to reformulate a hypothesis for the origin of this accession. As the major chromosome set was made up of 36 chromosomes and the minor by six univalents, this accession could be a heptaploid $(2 \mathrm{n}=7 \mathrm{x}=42)$ derived from $\mathrm{x}=6$. As pointed out, $\mathrm{x}=6$ had been recently reported in $B$. dictyoneura (Risso-Pascotto et al., 2006a). Brachiaria dictyoneura and B. humidicola are closely related species, belonging to the same taxonomic group (Group 6) and, at times, they have been confused by agronomists (Renvoize et al., 1996). The cytological evidence obtained from the meiotic behavior in this accession suggests that a male apomictic hexaploid genitor $(2 \mathrm{n}=6 \mathrm{x}=36)$ contributed with unreduced gametes $n=36$ and a sexual diploid female $(2 n=2 x=12)$, with $n=6$. At least two different mechanisms have been found in the genus Brachiaria as being responsible for the formation of unreduced gametes, and one of them was recorded in one accession of $B$. humidicola recently analyzed (Boldrini et al., 2006). The constant presence of six univalents at diakinesis and metaphase I suggests that both genomes are not closely related and that the present accession was originated by interspecific hybridization. Other evidence towards the union of two distinct genomes is the occurrence of cells with two nucleoli in prophase I, where each genome would organize its own nucleolus. The cytological evidence obtained from the six laggard univalents at anaphase I of H030 suggests that a diploid accession $2 n=2 x=12$ was probably the female genitor. This accession could represent the lost link with the ancestral basic chromosome number $(\mathrm{x}=6)$ in the Poaceae.

The analysis of meiotic behavior allows for the determination of relative affinities between genomes in a hybrid. There is strong evidence that allopolyploidization has played a very important role in the evolution of crop plants, including the Poaceae (Sybenga, 1992). However, little is known about the origin of natural allopolyploids. According to Harlan and De Wet (1975), allopolyploids probably originated from spontaneous hybridization followed by meiotic doubling, but their origin is difficult to establish. Despite the economic and agronomic importance of the genus and the prevalence of polyploid forms in Brachiaria, nothing is known about its evolutionary history. Genomes have not yet been identified in the genus. A unique study reports karyotype characteristics for some species (Bernini and Marin-Morales, 2001), but differences could not be established among them using conventional staining.

In an interspecific hybrid, the lack of affinity between genomes frequently results in sterility because of aberrant meiotic and mitotic divisions. Normal chromosome pairing and seed fertility are restored by doubling of chromosomes. Thus, most allopolyploids are tetra- or hexaploids (Singh, 1993). In the present accession, the doubling of chromosomes did not yet occur. However, if doubling ever occurs, the accession will be $2 n=14 x=84$. Such chromosome number was never reported in the genus until now. Although polyploidy is predominant 
in Brachiaria, high levels of ploidy are not common. The highest chromosome number in the genus $(2 \mathrm{n}=10 \mathrm{x}=90)$ was reported in B. bovonei (Spies and Du Plessis, 1986), and $2 \mathrm{n}=8 \mathrm{x}$ $=72$ in some other species (Takeota, 1965; Reeder, 1967). Allopolyploids are occasionally found in nature as spontaneous and transient events, or very rarely as established apomictics (Sybenga, 1992). The absence of accessions with high levels of ploidy in the genus resulting from the doubling of chromosomes of allopolyploids could be explained by its mode of reproduction. The present accession of $B$. humidicola, collected in the wild African savannas, reproduces by apomixis (apospory of the Panicum type; Valle CB, unpublished data), as do most polyploid accessions of Brachiaria (Valle and Savidan, 1996).

Due to ploidy differences among accessions and/or species and apomictic reproduction, hybridization in Brachiaria is not easily accomplished. To avoid barriers of sterility in the interspecific and interploid crosses, accessions in the agamic pool must necessarily have the same ploidy level. Sexual diploid accessions have been tetraploidized and used as female parents in crosses with natural apomictic males displaying relatively regular meiosis (Valle and Miles, 2001). Accessions with odd ploidy level and abnormal chromosome division, as found in the present accession of B. humidicola, generally display high frequencies of meiotic abnormalities resulting in low pollen fertility, which prevent their use in breeding programs.

\section{ACKNOWLEDGMENTS}

Research supported by UNIPASTO.

\section{REFERENCES}

Adams KL and Wendel JF (2005). Polyploidy and genome evolution in plants. Curr. Opin. Plant Biol. 8: 135-141.

Basappa GP, Muniyamma M and Chinnappa CC (1987). An investigation of chromosome numbers in the genus Brachiaria (Poaceae: Paniceae) in relation to morphology and taxonomy. Can. J. Bot. 65: 2297-2309.

Bernini C and Marin-Morales MA (2001). Karyotype analysis in Brachiaria (Poaceae) species. Cytobios 104: 157-171.

Boldrini KR, Pagliarini MS and do Valle CB (2006). Abnormal timing of cytokinesis in microsporogenesis in Brachiaria humidicola (Poaceae: Paniceae). J. Genet. 85: 225-228.

De Wet JMJ (1987). Hybridization and Polyploidy in the Poaceae. In: Grass: Systematics and Evolution (Soderstrom TR, Hilu WH, Campbell CS and Barkworth ME, eds.). Smithsonian Institution Press, Washington DC, 179-187.

Harlan JR and De Wet JMJ (1975). On Ö. Winge and a prayer: the origins of polyploidy. Bot. Rev. 41: 361-390.

Hilu KW (2004). Phylogenetics and chromosomal evolution in the Poaceae (grasses). Aust. J. Bot. 52: 13-22.

Keller-Grein G, Maass BL and Hanson J (1996). Natural Variation in Brachiaria and Existing Germplasm Collections. In: Brachiaria: Biology, Agronomy, and Improvement (Miles JW, Maass BL and Valle CB, eds.). CIAT/Embrapa, Cali, 17-42.

Mendes DV, Boldrini KR, Mendes-Bonato AB, Pagliarini MS, et al. (2006). Cytological evidence of natural hybridization in Brachiaria brizantha Stapf (Gramineae). Bot. J. Linn. Soc. 150: 441-446.

Mendes-Bonato AB, Pagliarini MS, Forli F, Valle CB, et al. (2002). Chromosome numbers and microsporogenesis in Brachiaria brizantha (Gramineae). Euphytica 125: 419-425.

Mendes-Bonato AB, Risso-Pascotto C, Pagliarini MS and Valle CB (2006). Chromosome number and meiotic behaviour in Brachiaria jubata (Gramineae). J. Genet. 85: 83-87.

Osborn TC (2004). The contribution of polyploidy to variation in Brassica species. Physiol. Plant. 121: 531-536.

Pannell JR, Obbard DJ and Buggs RJA (2004). Polyploidy and the sexual system: what can we learn from Mercurialis annua? Biol. J. Linn. Soc. 82: 547-560.

Penteado MIO, Santos ACM, Rodrigues IF, Valle CB, et al. (2000). Determinação de Poliploidia e Avaliação da Quantidade de DNA Total em Diferentes Espécies de Gênero Brachiaria. Boletim de Pesquisa, 11. Embrapa Gado de Corte, Campo Grande.

Reeder JR (1967). Notes on Mexican grasses. VI. Miscellaneous chromosome numbers. Bull. Torrey Bot. Club 94: 1-9. 
Renvoize SA, Clayton WD and Kabuye CHS (1996). Morphology, Taxonomy, and Natural Distribution of Brachiaria (Trin.) Griseb. In: Brachiaria: Biology, Agronomy, and Improvement (Miles JW, Maass BL and Valle CB, eds.). CIAT/Embrapa, Cali, 1-15.

Risso-Pascotto C, Pagliarini MS, Valle CB and Mendes-Bonato AB (2003). Chromosome number and microsporogenesis in a pentaploid accession of Brachiaria brizantha (Gramineae). Plant Breed. 122: 136-140.

Risso-Pascotto C, Pagliarini MS, Valle CB and Jank L (2004). Asynchronous meiotic rhythm as the cause of selective chromosome elimination in an interspecific Brachiaria hybrid. Plant Cell Rep. 22: 945-950.

Risso-Pascotto C, Pagliarini MS and Valle CB (2006a). A new basic chromosome number for the genus Brachiaria (Trin.) Griseb. (Poaceae: Panicoideae: Paniceae). Gen. Res. Crop Evol. 53: 7-10.

Risso-Pascotto C, Mendes DV, Silva N, Pagliarini MS, et al. (2006b). Evidence of allopolyploidy in Brachiaria brizantha (Poaceae: Paniceae) through chromosome arrangement at metaphase plate during microsporogenesis. Genet. Mol. Res. 5: 797-803.

Sharma ML (1979). Some considerations on the phylogeny and chromosomal evolution in grasses. Cytologia 44: 679-685. Singh R (1993). Plant Cytogenetics. CRC Press, Boca Raton.

Spies JJ and Du Plessis H (1986). Chromosome studies on African plants, I. Bothalia 16: 87-88.

Stebbins GL (1985). Polyploidy, hybridization, and the invasion of new habitats. Ann. Mo. Bot. Gard. 72: 824-832.

Sybenga J (1992). Cytogenetics in Plant Breeding. Springer-Verlag, Berlin.

Takeota T (1965). Chromosome numbers of some East African grasses. Am. J. Bot. 52: 864-873.

Utsunomiya KS, Pagliarini MS and do Valle CB (2005). Microsporogenesis in tetraploid accessions of Brachiaria nigropedata (Ficalho \& Hiern) Stapf (Gramineae). Biocell 29: 295-301.

Valle CB and Glienke C (1991). New sexual accessions in Brachiaria. Apomixis Newsl. 3: 11-13.

Valle CB and Savidan Y (1996). Genetics, Cytogenetics, and Reproductive Biology of Brachiaria. In: Brachiaria: Biology, Agronomy, and Improvement (Miles JW, Maass BL and Valle CB, eds.). CIAT/Embrapa, Cali, 147-163.

Valle CB and Miles JW (2001). Breeding of Apomictic Species. In: The Flowering of Apomixis: from Mechanisms to Genetic Engineering. CIMMYT; IRD; Comission, European, Mexico, 137-152. 